\title{
A EVASÃO NOS CURSOS DE ENGENHARIA EAD: ANÁLISE DE UM PROJETO PARA RETENÇÃO DOS ALUNOS NO CICLO BÁSICO.
}

\author{
LONDRINA/PR MAIO/2018
}

\author{
Marcio Ronald Sella - UNOPAR - marcio.sella@kroton.com.br \\ Marcela Navarro Pianucci - UNOPAR - marcela.pianucci@kroton.com.br \\ Nathália dos Santos Silva Nolepa - UNOPAR - nathaliad.silva@kroton.com.br \\ Eduardo Costa Estambasse - UNOPAR - eduardo.estambasse@kroton.com.br \\ Fernando Alves Negrão - UNOPAR - fernando.alves@kroton.com.br \\ Camila Fogaça De Oliveira - UNOPAR - camila.fogaca@kroton.com.br \\ Renata Karoline Fernandes - UNOPAR - renata.karoline@kroton.com.br \\ Bruno Cezar Scaramuzza - UNOPAR - bruno@unopar.br \\ Melina Klaus - UNOPAR - melina@unopar.br
}

Tipo: Investigação Científica (IC)

Natureza: Descrição de Projeto em Andamento

Categoria: Estratégias e Políticas

Setor Educacional: EDUCAÇÃO SUPERIOR

\begin{abstract}
RESUMO
O sistema brasileiro de Ensino Superior vem expandindo a oferta de cursos de engenharia e tem-se percebido o alto índice de evasão nesses cursos, que conforme a literatura supera $45 \%$. O fenômeno ainda é pouco evidenciado pelas instituições de ensino superior - IES, pois muitas delas estão mais focadas na captação de novos discentes e são poucas as IES brasileiras que possuem um programa institucional profissionalizado de combate à evasão. Dessa forma, o presente trabalho apresenta 0 projeto Estudos Continuados em Matemática, aplicado nas Instituições de Ensino Superior (IES) privadas, a Universidade Pitágoras Unopar e Universidade Anhanguera Uniderp, com o objetivo de auxiliar os alunos dos cursos de engenharia nos primeiros períodos com relação a dificuldades Matemáticas e assim, possivelmente minimizar a evasão, que tem grande relação com a reprovação nas disciplinas do ciclo básico. O projeto iniciou no segundo semestre de 2017 e tem como foco duas premissas, o nivelamento em Matemática Básica e as aulas de fixação de conteúdo. Atualmente, melhorias estão sendo implementadas de acordo com a resposta dos participantes e as evidências concretas até o momento permitiram inferir a respeito da satisfação com o aprendizado construído por meio desse projeto. Outro ponto relevante, é que o projeto atende não só a universidade, mas também a comunidade externa.
\end{abstract}

Palavras-chave: Engenharia EAD, Evasão, Estudos Continuados em Matemática. 


\section{INTRODUÇÃO}

O sistema brasileiro de Ensino Superior tem expandido consideravelmente nas últimas décadas. Um grande exemplo deste crescimento são os cursos Engenharia, que o número de profissionais egressos praticamente quadruplicou nos últimos anos. Segundo dados do INEP (2016), dos cursos ofertados pelas Instituições de Ensino Superior (IES) brasileiras, a Engenharia foi a área que mais cresceu no número de matrículas efetuadas e no número de alunos concluintes, sendo que esse fenômeno ocorreu de maneira mais evidente no setor privado de ensino.

$\mathrm{Na}$ década de 1960, os cursos de Engenharia eram destaques das universidades públicas, mas a partir de 1970 houve uma inversão nos índices e, atualmente, 80\% das IES que oferecem cursos na área de Engenharia são universidades privadas. Em oposição à essa expansão, a evasão ingressos vem se destacando e afligindo instituições de ensino em geral (OLIVEIRA et al., 2013).

O levantamento das causas que podem favorecer a evasão no Ensino Superior é um problema internacional e tem sido objeto de estudo de muitos trabalhos e pesquisas educacionais. A redução dos índices de evasão sempre foi um desafio das universidades que ainda hoje, passam por esse problema em diversos cursos superiores, principalmente entre as engenharias. Pois, a evasão, ou seja, as perdas de estudantes que iniciam e não terminam seus cursos, geram prejuízos para o país, acadêmicos e universidades.

Vale ressaltar, que a evasão não é um problema que afeta somente o setor público ou privado, mas sim ambos, pois é uma fonte de ociosidade de professores, funcionários, equipamentos e espaço físico. O que percebemos é uma grande preocupação das instituições de ensino superior - IES no setor privado em investir em marketing para a captação de novos discentes e poucas IES se preocupam em como manter os acadêmicos já matriculados. Segundo Silva Filho et al. (2007) são raríssimas as IES brasileiras que possuem um programa institucional profissionalizado de combate à evasão, com planejamento de ações, acompanhamento de resultados e coleta de experiências bem-sucedidas.

Neste sentido, o presente trabalho tem como objetivo apresentar o projeto Estudos Continuados em Matemática, aplicado na Instituição de Ensino Superior (IES) privadas, a Universidade Pitágoras Unopar e Universidade Anhanguera Uniderp, para auxiliar os alunos do ciclo básico com finalidade de retenção da evasão nos cursos de engenharia. As próximas seções deste artigo descrevem as etapas metodológicas realizadas neste 
trabalho. A seção 2 apresenta o referencial teórico relativo à evasão escolar. Em seguida, a seção 3 descreve a ferramenta Estudos Continuados em Matemática. Já a seção 4 apresenta e discute os resultados esperados com o projeto nos cursos de Engenharias. Finalmente, na sequência são discutidas as principais conclusões.

\section{REFERENCIAL TEÓRICO}

\subsection{Evasão Escolar no Ensino Superior}

O fenômeno da evasão do Ensino Superior brasileiro ainda é um estudo pouco explorado pela literatura, pois percebe-se, além da falta de trabalhos publicados, o baixo interesse das próprias IES brasileiras na busca do porque e como combater a evasão dos acadêmicos (SILVA, 2013). Isso ocorre porque há uma dificuldade no monitoramento dos alunos evadidos devido a diversidade de causas possíveis e de caráter muitas vezes subjetivo do motivo que leva à desistência discente, tornando assim, uma tarefa não trivial tentar antever se o aluno se manterá ou não até o término do curso (LOBO, 2012).

A evasão pode ser entendida sob dois aspectos similares, ou seja, a evasão anual média e a evasão total. O primeiro, mede qual a percentagem de alunos matriculados em uma instituição de ensino superior que, não tendo se formado, também não se matriculou no ano seguinte, por exemplo, se uma IES possui 120 alunos matriculados em um certo curso que poderiam renovar suas matrículas no ano seguinte, mas somente 90 renovaram, a evasão anual média no curso seria de $25 \%$. Já o segundo, mede o número de alunos que, tendo entrado num determinado curso, não obteve o diploma ao final de um certo número de anos, ou seja, se 120 estudantes entraram em um curso em um determinado ano e 65 se formaram, a evasão nesse curso é de aproximadamente 46\% (SILVA FILHO et al., 2017).

De acordo com a Comissão Especial do MEC para Estudo da Evasão (1996) as causas relacionadas a evasão dos alunos estão relacionadas as circunstâncias voltadas às características individuais dos alunos, como personalidade, dificuldades pessoais de adaptação à vida universitária; aos fatores internos às instituições, como currículos desatualizados, rígida cadeia de pré-requisitos, estrutura de apoio ao ensino insuficiente e aos fatores externos às instituições (como questões relativas ao mercado de trabalho, falta de reconhecimento social da carreira, desvalorização da profissão (HOED, 2016).

$\mathrm{Na}$ literatura são apresentadas diversas causas da evasão de alunos nos cursos superiores, como: as questões socioeconômicas, motivos vocacionais, motivos pessoas, 
doença grave, descontentamento acerca do método didático-pedagógico da instituição, tipo de instituição (se privada ou pública), transferência de domicílio, entre outros (GOMES et al., 2010). Outros autores, Silva Filho et al. (2007) e Gaioso (2005) afirmam que a falta de recursos é considerada uma das principais razões do acadêmico não prosseguir o estudo. Existem muitas causas de evasão em cursos de graduação e citadas por diversos autores (Barroso e Falcão, 2004; Andriola et al., 2006; Adachi, 2009; Giraffa e Mora, 2013).

\subsection{Evasão nos cursos de Engenharias}

A evasão nos cursos de Engenharia pode estar relacionada à deficiência na formação básica, bem como o domínio da língua pátria e hábitos de estudo e pesquisa (Martins et al., 2014). Os autores ressaltam ainda que as dificuldades do núcleo básico dos cursos se devem a falta de conhecimento de física e matemática o que aumenta a evasão e a retenção em média de $50 \%$ para cursos de engenharia no Brasil.

Hoed (2016) afirma que a questão vinculada à aprendizagem em matemática é um dos fatores entre as principais causas de evasão em cursos superiores. A evasão pode estar relacionada as reprovações em disciplinas nos quatro primeiros semestres dos cursos. Segundo o estudo de Gilioli (2016) as reprovações em disciplinas nos quatro primeiros semestres dos cursos nas décadas de 1980 e 1990 foram fatores essenciais para a evasão nos mesmos.

Os ingressantes em universidades particulares são, na grande maioria, estudantes que se formaram nas escolas públicas com formação deficiente e inadequada na Educação Básica (MELO, 2002). Um dos problemas que levam os alunos a desistirem dos cursos de Engenharia ao longo dos primeiros ciclos está relacionado as disciplinas da área de Matemática, Química e Física, que correspondem à uma parcela considerável na grade de Engenharia, tanto no ciclo básico quanto no ciclo profissionalizante.

Desta forma, a preocupação que vem surgindo, nas IES está direcionada ao fato de como preparar os alunos ingressantes para enfrentar os cursos de graduação com o mínimo de compreensão e criticidade, em um cenário que mostra que muitos chegam a esta etapa da escolarização com total despreparo para lidar, por exemplo, com os conceitos de Matemática Superior (GODOY e ALMEIDA, 2017).

As disciplinas de Matemática no Ensino Superior que representam os altos índices de reprovação são: Cálculo Diferencial e Integral, Cálculo Vetorial e Geometria Analítica (VILLARREAL, 1999). Isso pode se dar, devido a metodologia de ensino utilizada, como 
por exemplo, o ensino do Cálculo Diferencial e Integral que acaba sendo algoritmizado e sua aprendizagem se reduz, devido o acadêmico precisar memorizar e aplicar uma série de técnicas, regras e procedimentos (MELO, 2002). Com o mesmo ponto de vista, Barbosa e Borges Neto (1995) enfatizam que um dos fatores que interferem no rendimento do aluno é a maneira como são processados os conhecimentos. Além disso, a metodologia tradicional trata o conhecimento matemático como pronto e acabado, ou seja, o aluno é treinado para utilizar fórmulas, regras, não sendo, portanto, motivado a construir seu conhecimento. Desta forma, a aprendizagem se dá por meio de técnicas e memorização de fórmulas, normalmente, alheias ao modo pelo qual ocorreu a construção desse conhecimento.

Segundo Araújo e Moreira (2005), o grande número de repetências e evasões na disciplina Cálculo mostra ser necessário discutir mais as causas dos erros e buscar estratégias para solucionar. Assim sendo, torna-se de extrema relevância a ferramenta Estudos Continuados em Matemática desenvolvida e aplicada nas Universidade Pitágoras Unopar e Universidade Anhanguera Uniderp, com o objetivo de auxiliar na redução de repetências e possivelmente evasões das disciplinas de Matemática. $O$ projeto Estudos Continuados em Matemática está descrito a seguir.

\section{PROCEDIMENTOS METODOLÓGICOS}

Nesta etapa será apresentado de forma detalhada o projeto Estudos Continuados em Matemática, exemplificando os procedimentos realizados, as tecnologias utilizadas e 0 modo de como está sendo desenvolvido o projeto.

\subsection{Estudos Continuados em Matemática}

A proposta inovadora de um projeto com foco nos conteúdos de matemática surgiu na Universidade Pitágoras Unopar e Anhanguera Uniderp para os cursos EaD no segundo semestre 2017, com o objetivo de evitar que os alunos interrompam seus estudos por deficiência na sua formação básica com relação a Matemática. Neste escopo, além das Engenharias foram incluídos outros cursos que também possuem disciplinas com conteúdo matemático, como: Bacharelado em Administração, Bacharelado em Ciências Contábeis e Bacharelado em Economia; Curso de Licenciatura em Matemática; e Cursos Superiores Tecnológicos em Gestão Financeira e Processos Gerenciais, todos na modalidade à distância ou semipresencial.

O projeto de Estudos Continuados em Matemática, a cada semestre, passa pela etapa de planejamento que antecede aproximadamente 60 dias o início do período letivo. 
Nesta fase são relacionadas todas as disciplinas dos 07 cursos sinalizados anteriormente e os respectivos temas envolvendo a necessidade de cálculos.

Faz parte ainda da etapa de planejamento, a elaboração do cronograma para o semestre em questão com as respectivas datas bem como os docentes que ministrarão os temas definidos. Logo na sequência é feito a proposta de como serão ministradas as aulas de acordo com as 02 premissas:

I-Nivelamento em Matemática Básica: As teleaulas são ministradas ao vivo por dois professores simultaneamente, uma vez por semana e podem ser retransmitidas pelo Polo de apoio aos sábados. Durante a Teleaula de 90 minutos, existe um docente, com formação em matemática, disponível para fazer a mediação junto aos tutores presenciais/alunos utilizando as ferramentas existentes. Os temas apresentados nestas Teleaulas ao vivo são conteúdos matemáticos da Educação Básica, pré-requisto e necessários para cursar as disciplinas ofertadas no semestre vigente. Como via de regra, para tornar as aulas mais dinâmicas, é proposto dois docentes para cada encontro, como apresentado na Figura 1.

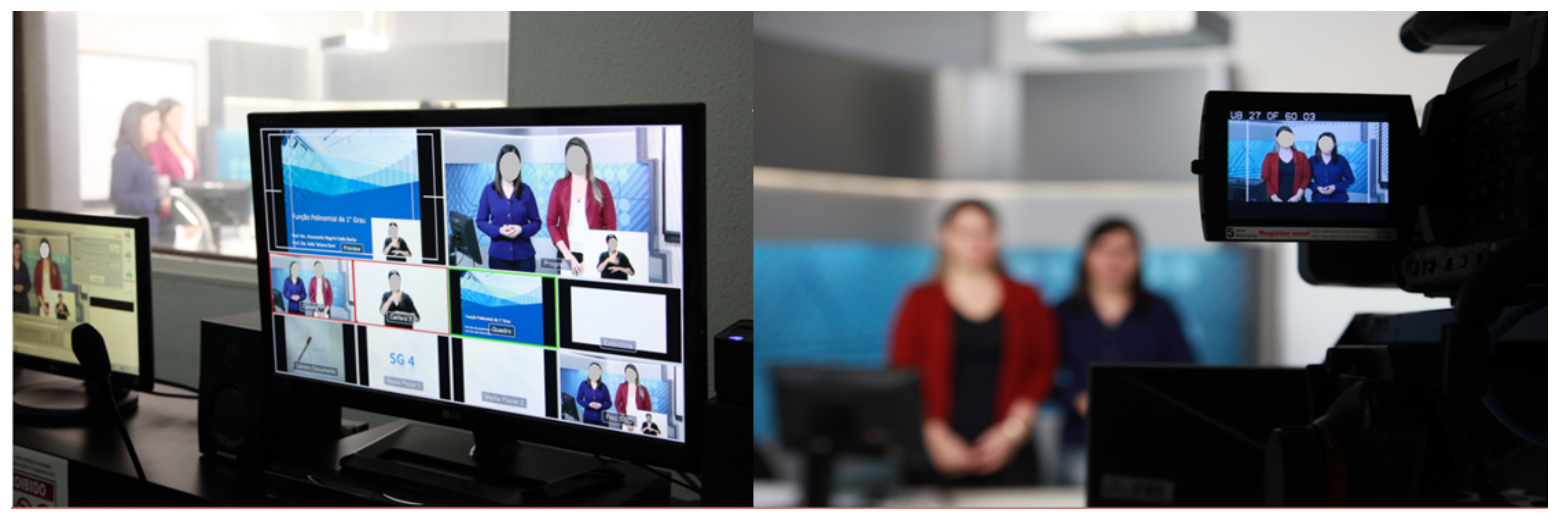

Figura 1: Imagens da Teleaula ao vivo - Nivelamento em Matemática Básica. Fonte: Elaborado pelos autores.

Outro aspecto é que os alunos, se assim preferirem, podem assistir as aulas com os conteúdos de nivelamento no seu Ambiente Virtual de Aprendizagem.

Il-Aulas de Fixação de Conteúdos: Têm foco na resolução de exercícios e são disponibilizadas no ambiente virtual de aprendizagem (AVA) aos estudantes. Se referem a 04 vídeo aulas para cada disciplina e são específicas para reforço dos estudantes. $O$ fluxograma da Figura 2 apresenta o processo descrito. 


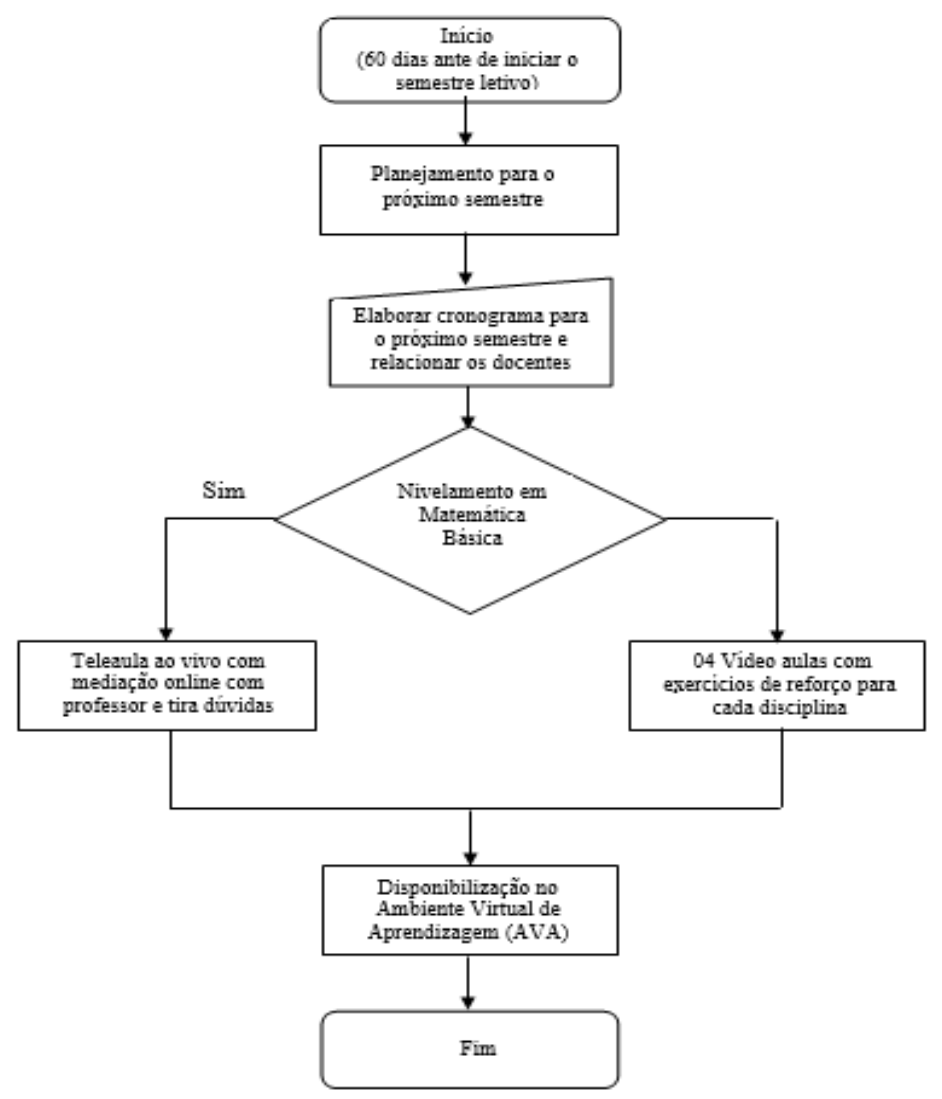

Figura 2: Fluxograma das etapas de elaboração do projeto - Estudos Continuados em Matemática. Fonte: Elaborado pelos autores.

\section{APRESENTAÇÃO E DISCUSSÃO DOS RESULTADOS}

O projeto Estudos Continuados em Matemática, por não ser uma atividade obrigatória para o aluno de graduação em Engenharia, não se tem o controle de frequência e além disso, o aluno pode optar por assistir as aulas do projeto em seu AVA. Neste momento, foi considerado o feedback relatado pelos polos de apoio e estudantes a respeito da qualidade e benefícios desse projeto. Os polos relataram que o projeto realizado no segundo semestre de 2017 foi amplamente elogiado pelos alunos, o que faz acreditar que será um grande sucesso no primeiro semestre de 2018. Já, os alunos, através do AVA, comentam nos Fóruns, com satisfação a respeito do aprendizado adquirido por meio desse projeto, conforme ilustra a Figura 3. 


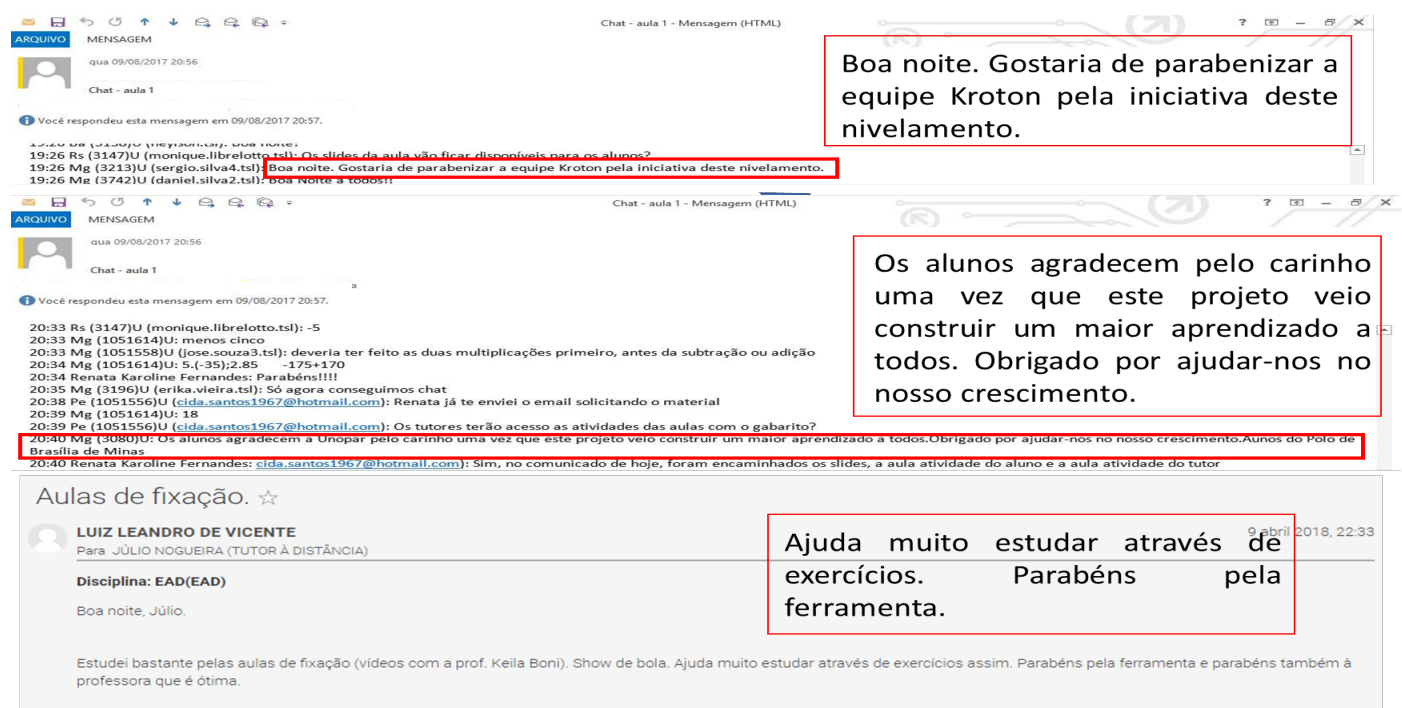

Figura 3: Relatos dos alunos a respeito do aprendizado adquirido no projeto. Fonte: Elaborado pelos autores.

\section{CONSIDERAÇÕES FINAIS}

O projeto Estudos Continuados em Matemática, teve seu início no segundo semestre de 2017 e continua em implantação de melhorias e finalização. Desde a sua concepção, não existe a necessidade de inscrição ou obrigatoriedade de frequência, visto que o principal objetivo é auxiliar o estudante, principalmente o estudante ingresso das Universidades Pitágoras Unopar e Anhanguera Uniderp a retomar e/ou construir conhecimentos Matemáticos que são essenciais para o bom desenvolvimento em seu curso de graduação.

Além da contribuição aos estudantes das IES anteriormente citadas, o projeto também teve potencial para contribuir para a formação da comunidade externa, visto que esse é um projeto gratuito e aberto a todos os interessados, independentemente se serem estudantes da IES, tendo assim, característica de extensão universitária. Mesmo com a impossibilidade de aferição da quantidade exata de estudantes que estão participando do projeto, visto que os estudante podem participar das aulas ao vivo, das aulas replicadas pelos polos aos sábados, ou ainda assistir as aulas em suas casas, ou onde preferirem pelo AVA, infere-se que o projeto vem agregando conhecimento matemático aos estudantes e tem grande aceitação, visto as mensagens encaminhadas pelos estudantes.

\section{REFERÊNCIAS BIBLIOGRÁFICAS}


Federal de Minas Gerais. Dissertação (Mestrado), Universidade Federal de Minas Gerais, Belo Horizonte, Minas Gerais - Brasil., 2009.

ANDRIOLA, W. B.; ANDRIOLA, C. G.; MOURA, C. P. Opiniões de docentes e de coordenadores acerca do fenômeno da evasão discente dos cursos de graduação da Universidade Federal do Ceará (UFC). Revista Ensaio: aval. pol. públ. Educ., 2006.

ARAÚJO, R.; MOREIRA, L. F. N. Monitoria da disciplina de Cálculo. In: 33ํㅡㄴ CONGRESSO BRASILEIRO DE EDUCAÇÃO EM ENGENHARIA, 2005, Campina Grande. Anais do 33 COBENGE: Promovendo e valorizando a Engenharia em um cenário de constantes mudanças. Campina Grande: ABENGE / UFPB, 2005, p. 1-5.

BARBOSA, G. O.; BORGES NETO, H. Raciocínio lógico formal e aprendizagem em Cálculo Diferencial e Integral: o caso da Universidade Federal do Ceará. Temas \& Debates, Blumenau, v. 8, n. 6, p. 63-73, 1995.

BARROSO, M. F.; FALCÃO E. B. M. Evasão universitária: O caso do instituto de física da UFRJ. In IX Encontro Nacional de Pesquisa em Ensino de Física, 2004.

GAIOSO, N. P. L. O fenômeno da evasão escolar na educação superior no Brasil. Dissertação (Mestrado em Educação) - Programa de Pós-Graduação em Educação da Universidade Católica de Brasília. Brasília, 2005.

GILIOLI, R. de S. P. Evasão em instituições federais de ensino superior no Brasil: expansão da rede, Sisu e desafios. Estudo técnico, 2016.

GIRAFFA, L. M. M. e MORA, M. C. Mineração de dados educacionais; oportunidades para o Brasil. In Tercera Conferencia LatinoAmericana Sobre El Abandono En La Educación Superior, Rio Grande do Sul - Brasil, 2013.

GODOY, E. V.; ALMEIDA E. A evasão nos cursos de Engenharia e a sua relação com a Matemática: uma análise a partir do COBENGE. Revista Educação Matemática Debate, Montes Claros, v. 1, n. 3, set./dez. 2017.

GOMES, M. J.; MONTEIRO, M.; DAMASCENO, A. M.; ALMEIDA, T. J. S.; DE CARVALHO, R. B. Evasão acadêmica no ensino superior: estudo na área da saúde. Revista Brasileira de Pesquisa em Saúde, v. 12, n. 1, p. 6-13, 2010.

HOED, R. M. Análise da evasão em cursos superiores: o caso da evasão em 
cursos superiores da área de Computação. Dissertação (Mestrado - Mestrado Profissional em Computação Aplicada) - Brasília, 2016. 188 p.

INSTITUTO NACIONAL DE ESTUDOS E PESQUISAS EDUCACIONAIS ANÍSIO TEIXEIRA - INEP (Brasília). Estatísticas da educação superior: graduação, 2016. http://portal.inep.gov.br/web/guest/sinopses-estatisticas-da-educacao-superior.

LOBO, M. B. C. M. Panorama da evasão no ensino superior brasileiro: aspectos gerais das causas e soluções. Associação Brasileira de Mantenedoras de Ensino Superior. Cadernos, n. 25, 2012.

MARTINS, T. A.; BITENCOURT, L. C.; BARBOSA, M. de L.; DOS SANTOS, L. R. Avaliação das condicionantes de retenção dos alunos de engenharia da UTFPR: bases para propostas interventivas. Cuarta conferencia Latino Americana sobre el abano en la educacion superior, 2014.

MELO, J. M. R. Conceito de Integral: uma proposta computacional para seu ensino e aprendizagem. 2002. 180f. Dissertação (Mestrado em Educação Matemática) Faculdade de Ciências Exatas e Tecnologias. Pontifícia Universidade Católica de São Paulo, 2002.

OLIVEIRA, V. F.; DE ALMEIDA, N. N., CARVALHO, D. M. de; PEREIRA, F. A. A. Um estudo sobre a expansão na formação em engenharia no Brasil. Revista de ensino de engenharia. Revista de Ensino de Engenharia da ABENGE, v. 32, p. 29-44, 2013.

SILVA FILHO, R. L. L.; MOTEJUNAS, P. R.; HIPÓLITO, O.; MELO LOBO, M. B. C. A Evasão no ensino superior brasileiro: instituto lobo para o desenvolvimento da educação, da ciência e da tecnologia. Cadernos de Pesquisa. v. 37. n. 132, 2007.

SILVA, Glauco Peres. Análise de evasão no ensino superior: uma proposta de diagnóstico de seus determinantes. Avaliação, v. 18, n. 2, p. 311-333, jul. 2013.

VILLARREAL, Mônica. E. O pensamento matemático de estudantes universitários de Cálculo e tecnologias informáticas. 1999. 402f. Tese (Doutorado em Educação Matemática) - Instituto de Geociências e Ciências Exatas. Universidade Estadual Paulista. Rio Claro, 1999. 